\title{
Perception of Online Learning Among Students From India Set Against the Pandemic
}

\author{
Felix Bast* \\ Department of Botany, Central University of Punjab, Bathinda, India
}

India is the second-most populous country in the world. There had been a tremendous shift towards online learning through Indian Government's digital initiatives in general, and during COVID-19 lockdown in particular. An online self-report survey $(n=1,318)$ was conducted to assess students' perception of online learning in this changed situation in comparison with traditional classroom learning. The study analysed eight independent variables on student's perception towards online learning, viz., gender, nature of the settlement, economic background, religiosity, primary electronic device, technologyreceptiveness, age, and educational institution, with each of these variables forming respective research hypotheses. Results revealed several exciting facets of students' perceptions. Receptiveness towards online learning was significantly higher for students from urban areas compared with rural areas. Possible reasons for these results are

OPEN ACCESS

Edited by:

Betina Silva-Lopes,

University of Aveiro, Portugal

Reviewed by:

Dorian Gorgan,

Technical University of Cluj-Napoca,

Romania

Tania Regina Da Rocha Unglaub, Santa Catarina State University, Brazil

*Correspondence:

Felix Bast

felix.bast@gmail.com

Specialty section: This article was submitted to

Digital Education,

a section of the journal

Frontiers in Education

Received: 04 May 2021 Accepted: 02 August 2021 Published: 18 August 2021

Citation:

Bast F (2021) Perception of Online Learning Among Students From India

Set Against the Pandemic.

Front. Educ. 6:705013.

doi: 10.3389/feduc.2021.705013 discussed, impediments to student's motivation with digital education are identified and the findings are contextualized in a broader perspective.

Keywords: e-learning, digital divide, digital inclusion, MOOC, online education

\section{INTRODUCTION}

For thousands of years, education and training that displayed within a triangle of school-teacherstudent has now utilized new, multifaceted, multi-channel alternatives with the help of technologies in the education system. One of them is "online learning."

The term "online learning" is used in this paper to refer to distance learning happening via online mode. The term not only encompasses full-fledged formal online courses, the so-called Massively Open Online Courses (MOOCs), but also supplementation of regular classroom learning with online content dissemination and interaction, the so-called flipped classroom or blended mode. Online learning is a core component of our stride towards achieving No. 4 of UN Sustainable Developmental Goals (UN-SDGs), quality education. While "quality education" itself is abstract and it has many meanings (Unterhalter, 2019), facilitating effective teaching-learning through online mode has become ever more relevant in post-COVID-19 pandemic era. The response from educational research pertaining to e-learning is expected to be a key component of UN 2030 agenda for sustainable development (Agbedahin, 2019).

Perception of students towards online learning is vital because a leading factor contributing in loss of student motivation and persistence is negative perceptions about online learning in general (Kauffman, 2015). Previous studies have identified several critical factors influencing online learning from a student's perspective, including having a computer at home (Volery and Lord, 2000), gender (Colley et al., 1994), regular instructions and feedback from teachers (Gaytan, 2015), sense of belonging to the learning community, family support, and time management skills (Hart, 2012), 
course content and design characteristics (Kauffman, 2015; Hone and El Said, 2016), and overall perception of quality (Hunter Dr. and Ross, 2019). All these factors contribute to the retention rate of MOOCs-fraction of initial registrants who completes the course-as student's perception is the primary determinant behind drop-outs (Hone and El Said, 2016). While men, in general, were more receptive to computers (Bahar and Asil, 2018), a recent survey conducted in India revealed a higher prevalence of smartphone use in female students than in male students (Nayak, 2018). However, no data available on which primary digital device (phone vs. computer) students use to access online courses.

\section{BACKGROUND}

Detailed surveys of student's perceptions about online learning have been scanty in India, the second-most populous country in the world. Among a few studies that have addressed this issue, one study concluded the following: "students who embraced online learning felt positive about e-learning," which is rather a circular logic (Kalyanasundaram and Madhavi, 2019). Yet another study conducted among medical students suggested student motivation, interest and contact time between students and facilitator influenced receptiveness (Grover et al., 2018). In yet another purported study, authors wrote the paper in bullet points to merely highlight the massive success of government schemes including SWAYAM and e-PG Pathshala during COVID-19 lockdown in India without any primary research undertaken my themselves (Jena, 2020). A generalized review on strengths, weaknesses, opportunities and challenges of online education in India did not reveal any new paradigms on student perceptions about online learning as well (Dhawan, 2020). There had been a gradual push towards online learning in general through union government's program promoting online business in general ("Digital India") and the Government's flagship program promoting e-Learning in particular ("Swayam"). A tremendous shift towards online learning happened during COVID-19 lockdown period where almost $100 \%$ of teaching-learning activities occurred via the internet. Meanwhile, COVID-19 has given educators time to rethink education and to address paradigms of education. However, with a Gini index of 37.8 as per World Bank (2011), income inequality is very high in India with considerable classdivide. "Digital divide" has been a trending term in recent years, yet no comprehensive study analysed this issue in context with online learning in India. At 105th position (Belson et al., 2017) internet speed in India is amongst the lowest in the world. Besides, roughly $68.8 \%$ of Indians live in rural areas (Chandramouli, 2011) where internet receptivity is much more inadequate than in urban areas.

On the other hand, religiosity is extremely high in India. According to the 2011 Census of India, 99.73\% of Indians identified oneself with a religion (Chandramouli, 2011). Previous studies have shown that students from countries with higher religiosity perform lower in STEM subjects (Stoet and Geary, 2017).

\section{MAIN FOCUS OF THE PAPER}

\section{Issues, Controversies, Problems}

Barring a few small-sample studies targeted to a specific domain of students, there had been no large-scale study in India during COVID-19 lockdown period that looked at receptivity of digital transformation from a student's perspective during the pandemic. Till date no survey assessed associations with factors such as economic background, religiosity, age, gender, "digital divide", and self-declared technology receptiveness. Another important lacuna that previous studies did not address had been how the choice of primary device (mobile phone/tablet vs desktop/laptop) students use to access online course might contribute in perception towards online learning in general.

To address these lacunae, the objectives of this study had been association of eight independent variables on student's perception towards digital education. The variables analyzed in this study are gender, nature of the settlement, economic background, religiosity, primary electronic device, technologyreceptiveness, age, and educational institution, with each of these variables forming respective research hypotheses. The rationale had been to find the ways to increase student's motivation by rationally identifying the roadblocks that impede effective teaching-learning framework in digital education.

\section{METHODOLOGY}

An online survey was conducted using Google forms between 15th May and May 25, 2020. The questionnaire was developed in lines with other similar surveys conducted elsewhere (Opalinski, 2001; Hone and El Said, 2016). However, the survey included several questions to test various hypotheses that are being tested in this study. As the study was cross-sectional with anonymous online feedbacks, tests of reliability such as test-retest forms could not be used. A survey of 100 participants was conducted (results not presented) prior to the main survey as a pilot study to test the questionnaire validity. All statistical tests were performed and found to be adequate to assess the significance of differences. The pilot study was also used to estimate the required sample size, to get adequate statistical power at $95 \%$ confidence level. No change in the questionnaire was deemed necessary from the pilot study. Inclusion criteria employed for participant recruitment: a current student registered at an educational institution in India. Exclusion criteria: participants from abroad and people who are not a registered student. The survey was e-mailed to all students at Central University of Punjab, India and the students who have taken a MOOC course (Biostatistics and Mathematical Biology offered through Indian Union Government's UGC-Swayam). The survey was also made open to the general public through online forums, including Reddit, Twitter, and Facebook. As the participants adequately represent the Indian population's demography in general, the survey is reproducible to a great extent. As the sample included a random subset of Indian students, the survey can be considered a representation of a larger population. Socio-demographic 
TABLE 1 | Specific statements to which the survey asked for the agreement (Agree or Disagree).

\begin{tabular}{ll} 
Question no & \\
\hline Q1 & For me, e-mail is an important communication tool \\
Q2 & I consider myself as someone who is receptive to technology adoption like searching the internet for help \\
Q3 & I consider internet-based technologies bring more harm than good to humanity in general \\
Q4 & I consider flexitime (ability to pause and watch the videos again, and take classes even when you are absent on the \\
& scheduled day) as a big advantage of online learning compared with regular classroom learning \\
Q5 & I consider the ability to spend more time with my family as a big advantage of online learning compared with regular \\
Q6 & classroom learning \\
Q7 & I get more distracted during online learning than regular classroom learning \\
Q8 & I tend to procrastinate (delay things like late submission of term papers) more in online learning than regular classroom \\
learning & I consider interacting with my classmates and teachers through online interactions during this COVID-19 helped me \\
Q9 & emotionally as a respite from loneliness \\
I10 & Overall, I consider online learning as good as regular classroom learning
\end{tabular}

characteristics of respondents were identified in a set of sevel initial questions, including gender, age, religiosity, educational institutions, settlement, primary device and economy. The survey is accessible at https://bit.ly/OnlineLearnSurvey, specific statements of which is provided in Table 1.

Although the Likert scale enabling the participants to respond based on their varying degree of agreement is commonly used in questionnaire surveys, such a system was not used in this survey for many reasons. As the resulting dataset would be in ordinal level, many significance tests with good statistical power (Fisher's exact test for instance) available for contingency tables cannot be applied. Studies have also shown that the Likert scale is no more advantageous than the simple dichotomous scale to decrease social desirability syndrome, a known factor contributing to response bias in questionnaire surveys (Medrano, 2011). Open ended questions and fill in the blanks responses would further exacerbate issues with subjective interpretation of responses, so as the reproducibility of the study.

The main response variable of the survey was the overall receptibility of students towards online learning (Q10). To measure student's receptibility towards technology in general, the survey included three questions (Q1-Q3). While Q2 was a direct question, Q1 and Q3 were formed to explore its utility as possible proxies. Specifically, Q3 was included as the statement is more philosophical ("digital scepticism" or technophobia) for the study to explore the possibility of associations. The survey also included questions to understand student's perceptions on some of the possible advantages (Q4, Q5, Q8, and Q9) and disadvantages (Q6 and Q7) of online learning in comparison with classroom learning. The survey's independent variables included gender (male, female, and other), nature of settlement (rural and urban), self-identified economic background (Lower middle class and Upper middle class/Affluent), religiosity (religious and non-religious), the primary device that the students use to access the online course (mobile phone/tablet and desktop/laptop age groups $(<20,21-30,31-40$, and $>40)$, and educational institution (School, College, State/Private university and Central University/IISER/IISc/IIT/TIFR/NIT/ CSIR/DST/DBT). As the study did not involve any sensitive questions, and as Prior Informed Consent was sought from the participants before they attempted the survey, no clearance from the Institutional Ethics Committee was deemed necessary. The survey also explicitly stated the following: "Please note that this is a general survey; class standards vary subject to subject. Students might have preferences for specific LMS platforms like Moodle, Google Classrooms/Slack/Jitsi/Meet etc. Your task is to choose an overall response honestly reflecting your view."

There were in total 1,320 responses, out of which two were from countries other than India. These two responses were excluded from further analyses. With 1,318 participants, this survey remains the most exhaustive data collection attempt in comparison with other similar surveys conducted during this period; for instance 77 participants in Agarwal and Kaushik (2020) and 307 in Muthuprasad et al. (2021). Responses were coded and collated in MS Excel, and further analyses were conducted in GraphPad Prism v8 (https:/www.graphpad.com/ scientific-software/prism/). All statistical tests were conducted at $0.05 \%$ significance level.

\section{RESULTS}

Socio-demographic characteristics of the participants are presented in Figure 1.

A summary of the overall responses received for the specific statements (Q1-Q10) is provided in Figure 2.

Approximately half of the participants (53.4\%) agreed with the main statement of the survey (Q10). As the focus of this study is about the responses received for this statement, the dataset was partitioned to explore associations of various independent variables with this response. Per cent agreement to Q10 as a factor of multiple independent variables (groups) is presented as Figure 3.

\section{Gender}

The survey received no responses from the third gender (response “other"). $52.6 \%$ female respondents and $54.81 \%$ of male respondents agreed with Q10. However, the differences were not significant (Fisher's exact test $p=0.4601$ ). 

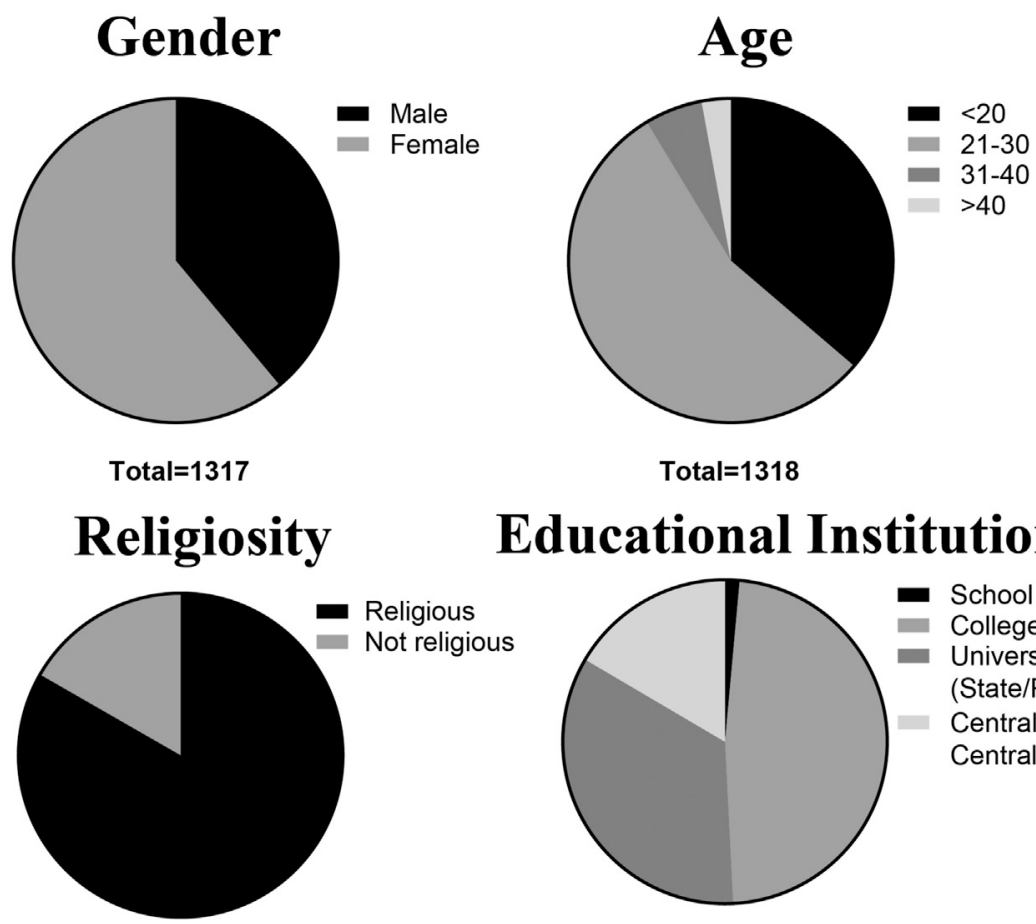

Educational Institutions

Total $=1318$

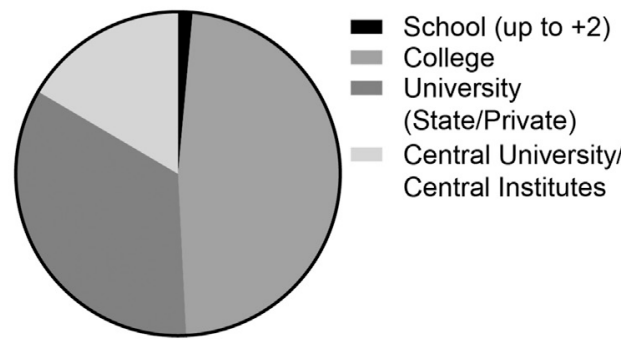

Total $=1313$

\section{Settlement}

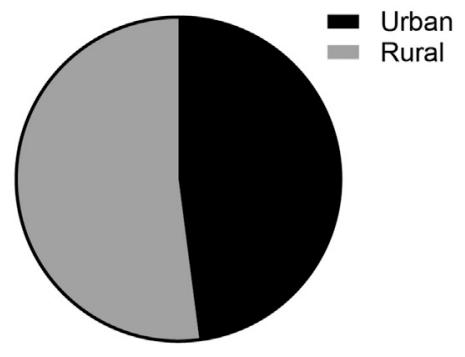

Primary Device

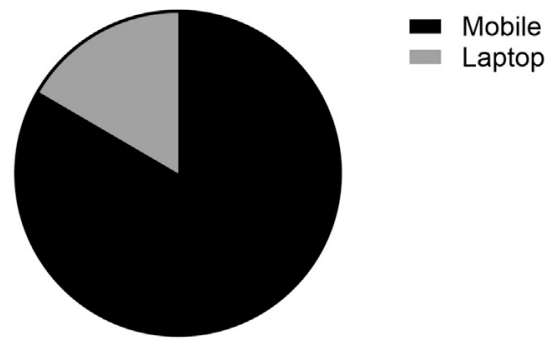

Total $=1318$

Economy

Total $=923$

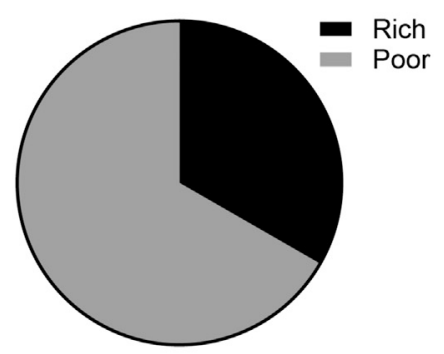

Total=1318

FIGURE 1 | Socio-demographic characteristics of the survey participants.

\section{Nature of Settlement}

$57.5 \%$ of respondents from urban areas and $49.7 \%$ from rural areas agreed with Q10. The differences were found to be statistically significant (Fisher's exact test $p=0.0056$ ).

\section{Economic Background}

$55.5 \%$ of respondents who identified themselves as 'rich' (upper-middle-class/affluent) and $52.2 \%$ of respondents who identified as "poor" (lower middle class) agreed with Q10. 


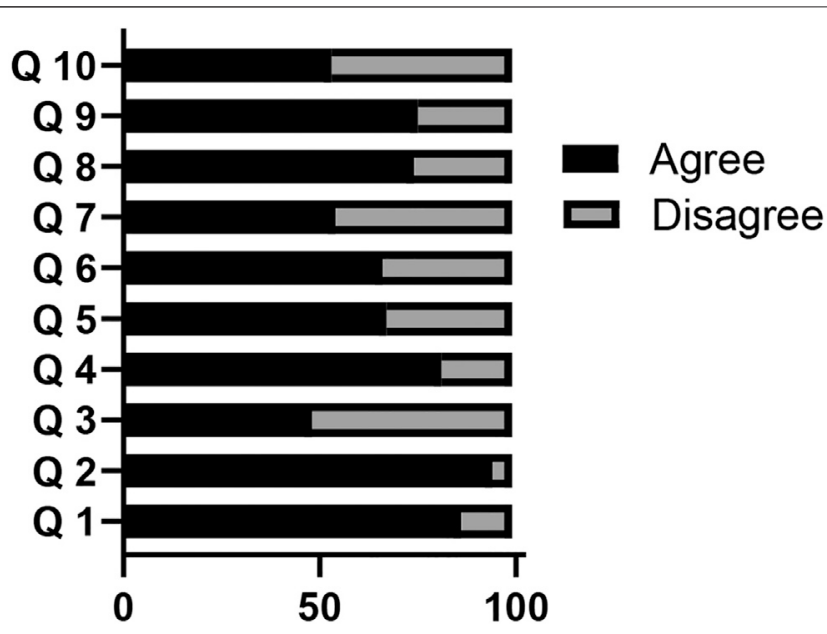

FIGURE 2 | Summary of responses received.

However, the differences were not significant (Fisher's exact test $p=0.2401)$.

\section{Technology Receptivity Proxy 1: "Digital Skepticism"}

Among the respondents who agreed with Q2, 53.4\% agreed with Q10 as well. On the other hand, among the respondents who disagreed with Q2, 53.3\% agreed with Q10. The differences were not significant (Fisher's exact test $p>0.9999$ ).

\section{Self-Declared Technological Receptiveness}

Among the respondents who agreed with Q3, 54.2\% agreed with Q10 as well. On the other hand, among the respondents who disagreed with Q3, 45.8\% agreed with Q10. The differences were found to be statistically significant (Fisher's exact test $p=0.0173)$.

\section{Technology Receptivity Proxy 2: E-mail as the Principal Mode of Communication}

Among the respondents who agreed with Q1, 55.9\% agreed with Q10 as well. On the other hand, among the respondents who disagreed with Q1, 37.9\% agreed with Q10. The differences were found to be statistically significant (Fisher's exact test $p<0.0001$ ).

\section{Religiosity}

$53.6 \%$ of respondents who declared as religious and $52.7 \%$ who reported as non-religious agreed with Q10. The differences were found to be not statistically significant (Fisher's exact test $p=$ 0.8245).

\section{Primary Digital Device}

Among the respondents who answered mobile phone/tablet as their primary digital device, 53.9\% agreed with Q10. On the other

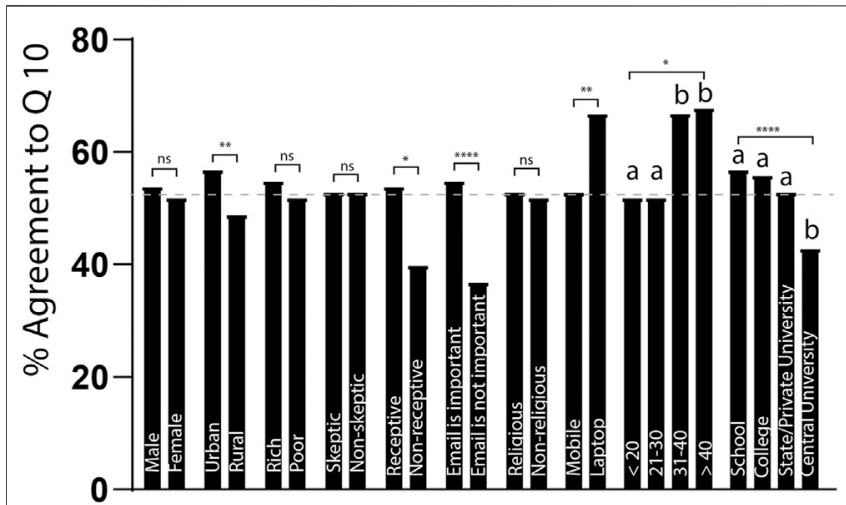

Various groups of respondents

FIGURE 3 | Per cent agreement to Q10 as a factor of various independent variables. The dashed line in grey represents the overall mean per cent agreement (53.4\%). Level of significance is presented above the column graphs. ns = not significant, ${ }^{\star} p<0.05,{ }^{\star \star} p<0.01,{ }^{\star \star \star} p<0.001,{ }^{* \star *} p<$ 0.0001 . Common lowercase letters on the top of plots identify statistically homogenous groups (post-hoc based on Bonferroni method). Refer text for types of tests performed.

hand, among the respondents who answered desktop/laptop as their primary digital device, 66\% agreed with Q10. The differences were found to be statistically significant (Fisher's exact test $p=0.0073$ ). Mobile phone usage was found to be significantly higher in females (87.3\%) than in males $(75.4 \%)$. These differences were found to be statistically significant (Fisher's exact test $p<0.0001$ ). On the other hand, Mobile phone usage was significantly higher in students from the lower economic background $(86.1 \%)$ than in those from the higher financial background $(78.3 \%)$. These differences were found to be statistically significant (Fisher's exact test $p=$ $0.0029)$.

\section{Age}

Among the age groups $<20,21-30,31-40$, and $>40,52.1,52,67.1$ and $68.4 \%$ agreed with Q10, respectively. Differences were found to be statistically significant $\left(X^{2}\right.$ test $\left.p=0.0073\right)$.

\section{Educational Institutions}

Respondents from School, College, "State/Private university" and "Central University/IISER/IISc/IIT/TIFR/NIT/CSIR/DST/DBT" showed agreement with Q10 at 57.9, 56.9, 53.8, and 43.3\%, respectively. The differences were found to be statistically significant (Fisher's exact test $p<0.0001$ ).

\section{Pros and Cons of Online Learning}

Results of the responses that specifically asked for student's perceptions about some of the possible advantages (Q4, Q5, Q8, and Q9) and disadvantages (Q6 and Q7) of online learning (Figure 2) revealed several interesting facets of information. Amongst the advantages of online learning, $81 \%$ of respondents perceived flexitime, $75.3 \%$ considered comfort of 
home, $74.3 \%$ regarded as emotional respite, and $67.8 \%$ thought the ability to spend time with family. Amongst the disadvantages, $66.8 \%$ considered distraction, while $54.5 \%$ considered the tendency for procrastination.

\section{SOLUTIONS AND RECOMMENDATIONS}

Among the demographic traits of survey respondents, noteworthy revelations include a very high proportion of religiosity (83.3\%), a high proportion of economically underprivileged $(66.7 \%)$, and a moderately high proportion of rural dwellers (52\%). While this study did not reveal any association of online learning receptibility with religiosity, economic status or gender, the overall trends revealed in this random sampling are expected to help plan the pedagogical strategies and policies. The survey also revealed an overwhelming proportion of students access online learning through their mobile devices (83.4\%). This finding is significant because it would enable the teachers and instructional designers of online courses to target mobile operating systems instead of desktop operating systems to ensure optimal content accessibility.

More importantly, the survey revealed several exciting facets of the student's perceptions of online teaching. Students from urban settlements (57.4\%) were significantly higher to be receptive about online learning compared with those from the rural settlement $(49.7 \%)$. One of the possible reasons is low internet speed, common in rural locations throughout India hampering multimedia content accessibility. Urban dwellers might also be financially stronger than rural counterparts, though no direct association of online learning receptibility with the economic background was evident in this study. It is noteworthy that the rich (55.8\%) were marginally more receptive than the poor (52.2\%) albeit statistically insignificant.

Another significant finding of this study is the direct relationship between technological receptiveness and online learning receptibility. Both self-reported technological receptiveness and the consideration that e-mail as an essential mode of communication correlated significantly with their receptibility towards online learning. Link with e-mail receptibility is interesting because young adults in India use their mobile phones principally for social media including Facebook, WhatsApp, Tic Tok, etc. Respondents who answered e-mail as an important communication tool might be an exception to this general trend such that they might inherently be having sober productivity-oriented digital habits. On the other hand, "digital skepticism" did not reveal any association with online learning receptibility in this study.

This study also revealed an interesting relationship between users of desktops/laptops with higher online learning receptibility. Possible reasons include better immersive experience with a bigger screen and more comfortable to read text from a computer. In addition, a vast majority of online learning content delivery in India is targeted towards desktops; this might very well be an underlying reason for the observed pattern. Like e-mail, laptop usage might have associated confounding variables that influence the students' overall receptibility towards online learning. For example, educated parents and an environment conducive to learning at home. The results indicate that the issue of digital adoption might very well be far more complicated than a simple binary between the haves and have nots, as the study failed to reveal any direct link with rich-poor divide.

On the other hand, the study showed higher computer usage among male students and students from economically privileged backgrounds. Like income inequality, gender inequality is very prominent in many families in India that are traditionally patrilineal (and patrilocal) with parents preferentially sending their sons to better schools. Results of this study also point to the same direction with "privileged gender" preferentially enjoying the luxury of more expensive computers.

The study also revealed an inverse trend of educational level and online learning receptivity; school children were more receptive than college students, and finally university students. Reasons for this paradoxical trend remain elusive, as the direction was in opposite to that observed for age. Perhaps adolescent (school) and teenage (college) students might feel good to spend time at their home during COVID-19 lockdown. That is, their receptiveness towards online learning might simply because they are more or less in a holiday-like situation. Or perhaps due to their emotional immaturity, they might have subconscious peer pressure to speak good about online learning in general, related to social desirability syndrome, a survey artefact. Central University students were the least receptive to online learning among various educational institute groups. As I work at a Central University, the survey might have attracted a disproportionate number of Central University participants as a platform to relay their discontentment towards online learning in general, a known form of response bias in questionnaire surveys. I have witnessed several dialogues by the current students about how online learning does not address inclusivity and digital divide, both in the campus and social media.

Among the perceived pros and cons of online learning, the survey revealed learning at home and family's comfort as a significant advantage of online education. This finding has ramifications while deciding the post-lockdown scenario with school and university education. As half of the participants agreeing in this survey that online education as good as the traditional classroom model and an overwhelming majority agreeing on many advantages of online education, these findings perhaps indicate that a mixed approach blending traditional classroom with online learning might just be the future of education.

Furthermore, as the students could download such videos, they can access it offline too any number of times without incurring additional internet expenses. The flexitime component of online education is especially relevant in developing countries where internet speed and bandwidth are often limiting factors in online education. The survey results corroborated my prior hypothesis that online education might serve as an emotional respite for the loneliness during COVID-19 lockdown. Role of online health communities and support groups for the emotional wellbeing of chronic patients are well-known 
(Bar-Lev, 2008; Wang et al., 2012). As far as my understanding, this is the first study that has divulged the positive attribute of online learning peer group interactions for the emotional wellbeing of students.

\section{CONCLUSIONS}

Receptiveness towards online learning in India during COVID19 lockdown period was significantly higher for students from urban areas compared with rural areas, students who used computers compared with those who used mobile devices, students who answered E-mail as their principal mode of communication with those who did not, and students who declared themselves as "technology-receptive" with those who did not. The study also revealed a direct relationship with age, with online learning receptibility significantly higher for respondents who are $>30$ years, and an inverse relationship with the level of educational institutions, with school students significantly more receptive than university students.

The finding that higher age group learners being more receptive towards online learning came as a surprise because a large number of studies have revealed a digital divide with age such that the elderly population, in general, are not receptive towards newer technologies (Loges and Jung, 2001; Neves et al., 2018). potential reasons for this disparity include a higher possibility of older youth to be employed such that she/he can afford better digital gadgets and internet connectivity. Another reason could be the older youth enrolling for online courses as part of their true "passion" rather than peer pressure to get a degree; they might have enough maturity to appreciate the goaloriented lifelong learning.

Computer usage was found to be significantly higher among male students and students from higher economic backgrounds. A higher prevalence of mobile phone usage among females revealed in this study corroborated similar finding reported earlier (Nayak, 2018). Amongst the advantages of online learning that students agreed upon including flexitime and emotional respite from loneliness during the lockdown. In contrast, disadvantages include more distractions and a higher tendency for procrastination.

Many participants considered flexitime as a definitive advantage of online learning. The finding is significant in multiple ways, as not all online education forms offer flexitime. For example, real-time synchronous lectures via videoconferencing (through Zoom, Jitsi, Google Meet etc.) have sky-rocketed during COVID-19 lockdown. In a recent paper, utility of Microsoft Teams was examined for online teaching-learning transformation during COVID-19 lockdown in India (Pal and Vanijja, 2020). However, such modes do not offer flexitime. A recent study conducted in the US revealed that the students perceive the instructor's use of synchronous sessions for interactions least helpful (Martin et al., 2018) suggestive of the same trend. Another recent study conducted in India during the same period also concluded that students prefer recorded lecture videos (Muthuprasad et al., 2021). Our finding suggests recording the contents and releasing it (for instance, via YouTube), has a significant advantage as the video can be accessed by the students any number of times.

\section{LIMITATIONS OF THE STUDY AND FUTURE RESEARCH DIRECTIONS}

As the survey was conducted online, only those with internet access could participate in the study. Additionally, as the survey was conducted in English, the sample represents only a subset of Indian students who understand English. The survey did not include questions to measure the geographical spread of responses, neither their majors (for graduate students). In addition, the survey did not address the impact of non-verbal cues on the receptiveness of online learning. Similar surveys to be conducted in future could potentially address these important issues to bring out more facets of online education in the country-a topic of exceptional importance for the 21st century. Afterall, COVID-19 pandemic has given educators and policy makers an opportunity to rethink about future education scenarios.

\section{DATA AVAILABILITY STATEMENT}

The raw data supporting the conclusions of this article will be made available by the authors, without undue reservation.

\section{ETHICS STATEMENT}

The studies involving human participants were reviewed and approved by the Institutional ethics committee, Central University of Punjab, Bathinda. The patients/participants provided their written informed consent to participate in this study.

\section{AUTHOR CONTRIBUTIONS}

The author confirms being the sole contributor of this work and has approved it for publication.

\section{ACKNOWLEDGMENTS}

I thank all the students who participated in this survey for their willingness and help to contribute to this study. Comments from two reviewers significantly improved this article. 


\section{REFERENCES}

Agarwal, S., and Kaushik, J. S. (2020). Student's Perception of Online Learning during COVID Pandemic. Indian J. Pediatr. 87, 554. doi:10.1007/s12098-02003327-7

Agbedahin, A. V. (2019). Sustainable Development, Education for Sustainable Development, and the 2030 Agenda for Sustainable Development: Emergence, Efficacy, eminence, and Future. Sustain. Develop. 27 (4), 669-680. doi:10.1002/ sd.1931

Bahar, M., and Asil, M. (2018). Attitude towards E-Assessment: Influence of Gender, Computer Usage and Level of Education. Open Learn. J. Open, Distance e-Learning 33 (3), 221-237. doi:10.1080/02680513.2018.1503529

Bank, W. (2011). GINI index (World Bank Estimate)| Data. Available at: https:// data.worldbank.org/indicator/SI.POV.GINI?locations=IN (Accessed 05 27, 2020).

Bar-Lev, S. (2008). "We Are Here to Give You Emotional Support”: Performing Emotions in an Online HIV/AIDS Support Group. Qual. Health Res. 18 (4), 509-521. doi:10.1177/1049732307311680

Belson, D., Thompson, J., Sun, J., Moller, R., Sintorn, M., and Huston, G. (2017). akamai's [state of the Internet] Q1 2017 Report. Cambridge, MA: Akamai Cambridge. doi:10.4337/9781785368806

Chandramouli, C. m. (2011). Census of india 2011. Provisional Population Totals. New Delhi: Government of India, 409-413.

Colley, A. M., Gale, M. T., and Harris, T. A. (1994). Effects of Gender Role Identity and Experience on Computer Attitude Components. J. Educ. Comput. Res. 10 (2), 129-137. doi:10.2190/8NA7-DAEY-GM8P-EUN5

Dhawan, S. (2020). Online Learning: A Panacea in the Time of COVID-19 Crisis. J. Educ. Technol. Syst. 49 (1), 5-22. doi:10.1177/0047239520934018

Gaytan, J. (2015). Comparing Faculty and Student Perceptions Regarding Factors that Affect Student Retention in Online Education. Am. J. Distance Educ. 29 (1), 56-66. doi:10.1080/08923647.2015.994365

Grover, S., Sood, N., and Chaudhary, A. (2018). Student Perception of Peer Teaching and Learning in Pathology: A Qualitative Analysis of Modified Seminars, Fishbowls, and Interactive Classroom Activities. Indian J. Pathol. Microbiol. 61 (4), 537. doi:10.4103/IJPM.IJPM_297_17

Hart, C. (2012). Factors Associated with Student Persistence in an Online Program of Study: A Review of the Literature. J. Interactive Online Learn. $11(1), 19$.

Hone, K. S., and El Said, G. R. (2016). Exploring the Factors Affecting MOOC Retention: A Survey Study. Comput. Educ. 98, 157-168. doi:10.1016/ j.compedu.2016.03.016

Hunter Dr, J., and Ross, B. (2019). Does Increased Online Interaction between Instructors and Students Positively Affect a Student's Perception of Quality for an Online Course?. J. Empowering Teach. Excell. 3 (2), 4. doi:10.15142/gwx5-jq07

Jena, P. K. (2020). Online Learning during Lockdown Period for Covid-19 in India. Int. J. Multidisciplinary Educ. Res. (Ijmer) 9, 82.

Kalyanasundaram, P., and Madhavi, C. (2019). Students' Perception on E-Learning-A Study of Online Certificate Courses. Int. J. Psychosocial Rehabil. 23 (1), 302. doi:10.37200/IJPR/V23I1/PR190239

Kauffman, H. (2015). A Review of Predictive Factors of Student success in and Satisfaction with Online Learning. Res. Learn. Technol. 23, 26507. doi:10.3402/ rlt.v23.26507

Loges, W. E., and Jung, J.-Y. (2001). Exploring the Digital Divide. Commun. Res. 28 (4), 536-562. doi:10.1177/009365001028004007
Martin, F., Wang, C., and Sadaf, A. (2018). Student Perception of Helpfulness of Facilitation Strategies that Enhance Instructor Presence, Connectedness, Engagement and Learning in Online Courses. Internet Higher Educ. 37, 52-65. doi:10.1016/j.iheduc.2018.01.003

Medrano, C. (2011). "The Effect of Dichotomous versus Likert Response Format on the Measurement of Socially Desirable Response Bias,", 2539.

Muthuprasad, T., Aiswarya, S., Aditya, K. S., and Jha, G. K. (2021). Students' Perception and Preference for Online Education in India during COVID -19 Pandemic. Social Sci. Humanities Open 3 (1), 100101. doi:10.1016/ j.ssaho.2020.100101

Nayak, J. K. (2018). Relationship Among Smartphone Usage, Addiction, Academic Performance and the Moderating Role of Gender: A Study of Higher Education Students in India. Comput. Educ. 123, 164-173. doi:10.1016/ j.compedu.2018.05.007

Neves, B. B., Waycott, J., and Malta, S. (2018). Old and Afraid of New Communication Technologies? Reconceptualising and Contesting the 'age-Based Digital divide'. J. Sociol. 54 (2), 236-248. doi:10.1177/ 1440783318766119

Opalinski, L. (2001). Older Adults and the Digital divide: Assessing Results of a Web-Based Survey. J. Technol. Hum. Serv. 18 (3-4), 203-221. doi:10.1300/ J017v18n03 13

Pal, D., and Vanijja, V. (2020). Perceived Usability Evaluation of Microsoft Teams as an Online Learning Platform during COVID-19 Using System Usability Scale and Technology Acceptance Model in India. Child. youth Serv. Rev. 119, 105535. doi:10.1016/j.childyouth.2020.105535

Stoet, G., and Geary, D. C. (2017). Students in Countries with Higher Levels of Religiosity Perform Lower in Science and Mathematics. Intelligence 62, 71-78. doi:10.1016/j.intell.2017.03.001

Unterhalter, E. (2019). The Many Meanings of Quality Education: Politics of Targets and Indicators inSDG4. Glob. Pol. 10, 39-51. doi:10.1111/17585899.12591

Volery, T., and Lord, D. (2000). Critical success Factors in Online Education. Intl Jnl Educ. Mgt 14 (5), 216-223. doi:10.1108/09513540010344731

Wang, Y.-C., Kraut, R., and Levine, J. M. (2012). "To Stay or Leave? the Relationship of Emotional and Informational Support to Commitment in Online Health Support Groups," in Proceedings of the ACM 2012 conference on Computer Supported Cooperative Work, Seatle, WA February 11-15, 2012. doi:10.1145/2145204.2145329

Conflict of Interest: The author declares that the research was conducted in the absence of any commercial or financial relationships that could be construed as a potential conflict of interest.

Publisher's Note: All claims expressed in this article are solely those of the authors and do not necessarily represent those of their affiliated organizations, or those of the publisher, the editors and the reviewers. Any product that may be evaluated in this article, or claim that may be made by its manufacturer, is not guaranteed or endorsed by the publisher.

Copyright (c) 2021 Bast. This is an open-access article distributed under the terms of the Creative Commons Attribution License (CC BY). The use, distribution or reproduction in other forums is permitted, provided the original author(s) and the copyright owner(s) are credited and that the original publication in this journal is cited, in accordance with accepted academic practice. No use, distribution or reproduction is permitted which does not comply with these terms. 